\title{
SIN OBJETO
}

\section{Epojé, Vanguardia y Fenomenología}

César Moreno

Universidade de Sevilla

\section{Tábula rasa (o Hágase la oscuridad)}

"Camaradas, alzáos, escapad a la tiranía de las cosas"

A pesar de su aparente serenidad, sin duda Cuadrado negro sobre fondo blanco (1915) (figura 1) y Cuadrado blanco sobre fondo blanco (1918) (figura 2), de Kassimir Malevich, son de los más inquietantes cuadros no únicamente de los movimientos de vanguardia del primer tercio del siglo $\mathrm{XX}$, sino probablemente de todo el siglo pasado. ${ }^{2}$ Cuadrado negro sobre fondo blanco detenta el privilegio (decisivo para la vanguardia en cuanto vanguardia) de representar una novedad en el ejercicio de la abstracción que llamaremos "radical" o minimalista, en tanto supone un ejercicio extremo de epojé o puesta entre paréntesis del mundo así llamado "objetivo", que había ocupado no sólo el modelo del realismo mimético de arte occidental, sino que se había mantenido aún, aunque sin duda trastomado, en los restos de figuración del impresionismo, el expresionismo, el cubismo e incluso, aunque imaginariamente muy metamorfoseado, en el surrealismo. Por su parte, y aunque con alguna incidencia más dinámica, Cuadrado blanco sobre fondo blanco supondría una "vuelta de tuerca" de aquella epojé. La diferencia entre las obras de 1915 y 1918 estriba en que en la primera el cuadrado negro (nocturno) hace

1 Cit. por Néret, G., Kasimir Malevich y el suprematismo, Taschen, Köln, 2003, p. 7.

2 Se encontrará un laudatorio y muy minucioso estudio del cuadro de Malevich en Wajcman, G., El objeto del siglo [1998], Amorrortu, Buenos Aires, 1998. Las sugerencias de Wajcman son demasiado prolijas como para que pudieran ser aquí objeto del minucioso comentario que se merecen por su lucidez. En cualquier caso, es un texto completamente recomendable para quien desee profundizar en el pensamiento en torno al Cuadrado negro. 
contraste con el fondo blanco, trabajando omnilateralmente con la discontinuidad negro/blanco, mientras que en el cuadrado blanco apenas si se produce ese contraste, desenvolviéndose en la continuidad de una claridad lechosa, blanquecina (matutina). Por otra parte, si bien el cuadrado negro ocupa casi todo el lienzo, en su parte central, dejando al fondo blanco pequeños márgenes a los cuatro lados, en el caso del cuadrado blanco se constata respecto a aquel hieratismo (de una aplastante armonía o cuadratura) que el cuadrado se ha desplazado como pretendiendo escapar del centro - o del Lienzo. Sin embargo, en Cuadrado negro sobre fondo blanco se da un sobrecogedor estatismo del Cuadrado. A diferencia de otros muchos trabajos de Malevich, aquí no hay dinamismo alguno: con toda seguridad no rodará este Cuadrado, que ocupa el centro del Lienzo, en hierático equilibrio. Ni el más mínimo desplazamiento. Como si no pudiera encontrarse en él, en su forma en el lienzo, ni inquietud, ni aspiración ni deseo - salvo la posición que ocupa, su forma cuadrada y su color -negro. Su milagro es que es profundo a pesar de ser plano. En el fondo - nunca mejor dicho - lo que importa de esta Forma es su despedida total o "hasta nunca" de la velocidad futurista y de la tortura/descomposición/rodeo cubista que supone: aparte de hierático, el Cuadrado carece de perspectivas, sólo posee la magia de su Negrura en cuadrilátero, de su eclipse o encubrimiento cuadrangular. Malevich se atrevió, de este modo, a dar un paso radical en el sentido de lo que él denominaba gegenstandlose Welt ["mundo sin objeto" o "inobjetivo", según las traducciones], en el que ya no se trataba simplemente de "abstracciones". En efecto, el "cuadrado negro" no es una abstracción más, sino una abstracción radical, y no sólo como fruto de una muy buscada despedida de los objetos, sino también como desconexión del propio pluralismo, la diversidad y la diversión de las distancias, diferencias y referencias que pudiesen provocar y exigir que en el acto perceptivo debieran aparecer objetos, producirse movimiento, activarse intenciones de atención particular y minuciosa, operaciones de búsqueda, interrogaciones con vistas a la localización de identidades (¿qué es esto, qué es aquello?, etc.). La “opción” o lo que podríamos llamar el "efecto Cuadrado-negro" pertenecen al imaginario de la Noche - sobre todo de la Noche de Juan de la Cruz - y el Desierto. ${ }^{3}$ Así, decía Malevich que "cuando en el año 1913, en un desesperado intento de liberar al arte de la rémora de la objetividad me refugié en la forma cuadrada y expuse una tela que no tenía otra cosa que un cuadrado negro sobre fondo

3 Cruz, Juan de la, "Coplas del alma que pena por ver a Dios..." 6, en el vol. Poesía y prosas, Alianza Ed. (Bolsillo, 912), Madrid, 1982, pp. 69-70. "En una noche oscura,/con ansias, en amores inflamada,/¡oh dichosa ventura!, /salí sin ser notada/estando ya mi casa sosegada. // A oscuras y segura,/por la secreta escala, disfrazada,/;oh dichosa ventura!,/a oscuras y en celada,/estando ya mi casa sosegada. //En la noche dichosa,/en secreto, que nadie me veía,/ni yo miraba cosa,/sin otra luz y guía/sino la que en el corazón ardía. //Aquésta me guiaba/más cierto que la luz de mediodía,/adonde me esperaba/quien yo bien me sabía,/en parte donde nadie parecía. $/ / ¡$ Oh noche que guiaste!/joh noche amable más que el alborada!/joh noche que juntaste/Amado con amada,/amada en el Amado transformada!". 
blanco, los críticos, y con ellos el público, dijeron: 'Todo lo que amamos ha desaparecido. Estamos en un desierto... ¡A Ante nosotros no hay otra cosa que un cuadrado negro sobre un fondo blanco!",4

\section{Instinto y abstracción (protogeometría).}

En realidad, todo estuvo preparado muy tempranamente en el siglo XX. El desafio de la abstracción había encontrado en 1908, en el estudio de Wilhelm Worringer sobre Abstracción y proyección, ${ }^{5}$ una justificación como resultado (la abstracción) de una pulsión primitiva, y en De lo espiritual en el arte (1910), de Wassily Kandinsky, su primera declaración específicamente artística. También el futurismo de los Severini, Carrà, Balla y Boccioni, y el orfismo de Robert y Sonia Delaunay habían practicado profusamente la abstracción. Pero quizás Worringer tenía en mientes otra abstracción - justamente más en la opción de Malevich. Worringer sitúa junto a la Einfühlung ${ }^{6}$ la tendencia a la abstracción como dos claves para comprender el origen del arte. A su juicio, si la geometría triunfó fue porque respondía a una pulsión profunda muy lejana, en sus orígenes, de cualquier afán de cálculo o medida, y derivadamente porque conectaba la "pulsión" abstractiva con lo que Worringer llama "agorafobia", un término quizás incorrecto para designar el rechazo, por parte del sujeto, del devenir, el caos del mundo, las formas y los espacios. ${ }^{7}$ De ser así, ello significaría que si la abstracción geométrica triunfó no se debió ante todo y primeramente a un racionalismo que se dejara complacer por la exactitud matemática y el modelo de cosmos noético inteligible que podría brindar la geometría (de Platón a Spinoza y más allá), sino a la fascinación perceptiva que las figuras ejercieron originalmente por instinto, pulsión o "necesidad elemental"8 sobre la sensibilidad y el pensamiento. ¿En qué habría

4 Malevich, K., "Suprematismo", incluido en Die gegenstandlose Welt (1927), recogido en Teorias del arte contemporáneo. Fuentes artísticas y opiniones críticas (H. B. Chipp), Akal, Madrid, 1995, p. 367.

5 Incluido en Worringer, W., Abstracción y naturaleza [1908], (trad. Mariana Frenk), FCE (Breviarios, 80), México, 1975, pp. 17-39.

6 "Proyección afectiva", en la traducción del texto de Worringer que manejamos.

7 "Mientras que el afán de proyección sentimental está condicionado por una venturosa y confiada comunicación panteísta entre el hombre y los fenómenos del mundo circundante, el afán de abstracción es consecuencia de una intensa inquietud del hombre ante esos fenómenos y corresponde, en la esfera religiosa, a un sesgo acusadamente trascendental de todas las representacioens. Quisiéramos darle a esta actitud el nombre de inmensa agorafobia espiritual" (ibíd., p. 30).

8 Para Worringer,"sería desconocer las condiciones psicológicas de las cuales nació la forma artística si dijéramos que lo que al hombre le había hecho aspirar a la regularidad geométrica era el ansia de sujeción a la ley, pues esto supondría una compenetración intelectual-espiritual de la forma geométrica y la haría aparecer como producto de la reflexión y del cálculo. Más bien estamos autorizados a suponer que aquí se trata de una creación puramente instintiva; 
consistido, entonces, el logro del Cuadrado, o del Cuadrángulo, de Malevich, y sus vástagos suprematistas? Con toda probabilidad no se trataba sólo de una emblemática figura geométrica, sino del Negro. Cuadrado y Negro. Semejante combinación debía no sólo ofrecer aplomo, confianza o serenidad sino también liberar por el Borrado, la Anulación y el Desasimiento. En este Cuadrado Negro la vanguardia ya no es la de la velocidad, la acumulación, la simultaneidad, el ruido, lo informe, el caos o la relacionalidad delirante (o poética), sino sencillamente la vanguardia del "Cero". Un Cero como una ventana o, si se me permite decirlo así, como un espacióculo abierto a una inmensidad íntima (en conocida expresión de Gaston Bachelard), conmovedora de y para una subjetividad casi desconocida, a partir de ahora correlacionada con el No-Objeto. En nombre de las duras exigencias de la "necesidad interior" (Kandinsky) había madurado la insatisfacción, al menos en Malevich, ante la aventura cubofuturista, torturante y vertiginosa, ${ }^{9}$ de la que son magníficos ejemplos, en el propio Malevich, sus obras "El afilador" y "Vaca y violín" (ambas de 1912-1913) (figuras 3 y 4) o "Un inglés en Moscú" (1914). Había llegado el momento - histórico e intrapictórico- de conquistar una nueva sere-

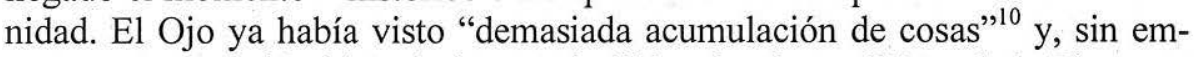
bargo, aún no lo decisivo, lo imprescindible, el reducto último de la Pintura y de la Imagen en su "grado cero". Demasiado vértigo y descomposición de

que el afán de abstracción se forjó esta forma de acuerdo con una necesidad elemental, sin intervención del intelecto. Debido precisamente a que todavía el intelecto no había debilitado el instinto, la predisposición - existente ya en la célula germinal - a la sujeción a ley podía encontrar la expresión abstracta para ella. Las formas abstractas, sujetas a ley, son, pues, las únicas y supremas en que el hombre puede descansar ante el inmenso caos del panorama universal" (ibíd., p. 33). Y sigue, un poco más adelante: "Establecemos, pues, la proposición siguiente: la simple línea y su desarrollo de acuerdo con la sujeción a una ley puramente geométrica, debía ofrecer la mayor posibilidad de dicha al hombre confundido por la caprichosidad y confusión de los fenómenos. Pues en ella está eliminado hasta el último residuo de un nexo vital y una dependencia de la vida; con ella está alcanzada la forma absoluta, suprema, la abstracción pura." Es de notar el uso, por parte de Worringer, del adjetivo "suprema" que quizás pudo sugerir a Malevich el nombre de su aportación de vanguardia.

9 Worringer cita a Hildebrand (El problema de la forma, 1893 - hay ed. castellana en Visor, La balsa de la Medusa, a cargo de Francisca Pérez Carreño), en un texto que resulta sumamente esclarecedor. El texto de Hildebrand dice: "Pues la tarea de la plástica no es dejar seguir al espectador con ese malestar que le causa su visión inconclusa frente a lo tridimensional o cúbico de la impresión natural y que le obliga a hacer un gran esfuerzo por formarse él mismo una clara representación visual; su tarea consiste más bien en proporcionarle esta representación visual y con esto quitar a lo cúbico lo torturarte. Mientras una figura plástica impresiona en primer lugar como un algo cúbico, está todavía en la etapa inicial de su creación artística; sólo cuando a pesar de ser cúbica da la impresión de un algo plano, ha logrado una forma artística" (Worringer, W., op. cit., pp. 36-37). Por cierto, en Die gegenstandlose Welt Malevich parece asumir por completo la doctrina de Worringer, cuando "deduce" una columan antigua del sentimiento que provoca en el que la contempla (independientemente de su utilidad práctica) o un avión del anhelo de velocidad (Malevich. K., "Suprematismo", art. cit., p. 369.

${ }^{10}$ Malevich, K., ibid., p. 368 
formas: perritos que parecían ciempiés (en el famoso cuadro de Giacomo Balla, de 1912 -figura 5), o Torres Eiffels que se derrumbaban y aros multicolores (en Robert Delaunay, en cuadros que datan respectivamente, de 1910 y 1913)... Hacía falta el Cuadrado Negro. Nada Más. Los repertorios de imágenes que le acompañan son insignificantes a su lado, junto a su imponente Presencia. Su estela llega hasta el expresionismo abstracto norteamericano de postguerra, especialmente a partir de 1950, con los obsesivos colour fields de Mark Rothko (figura 6) (por ejemplo, su "núm. 8", de 1964, casi completamente negro) y las abstraciones radicales de Rauschenberg y, más tarde, Ad Reinhardt. Pero fue entre 1913 y 1915 cuando tuvo lugar la regresión al CERO, la urgencia - en Malevich - de retornar o afianzarse en lo Mínimo o el fundamento. Había nacido la abstracción minimalista. Si el lema había sido y era aún: despedida-del- "mundo objetivo", y si la exigencia aún era, de veras, la de aprender-a-ver, ya no bastaba acosar sin más lo real, los objetos y percepciones, sino que se debía dar implacablemente, sin miramientos ni piedad, el jaque mate a esa cruda realidad de los hechos "cotidianos" del mundo utilitario, consumar el apocalipsis de las cosas que pudiesen distraer de la aventura mística de la interioridad... Si se trataba de eso, por más loco que pudiera parecer, había-que-pintar-un-cuadrado-negro; era necesario simular el No-Ver en un lienzo de $79 \times 79 \mathrm{cms}$. para rescatar el momento primigenio del emerger (o aparecer) de lo Ínfimo.

\section{Cuadrado, Negro}

Si hubiese sido Blanco, habría quedado desactivada la potencia crítica, al suscitar casi natural o espontáneamente el proyecto de pintarlo, garabatearlo, emborronarlo (pasión, como se sabe, del graffiti urbano contemporáneo)... Sin embargo, el reto consistía en borrar, desquitarse (al menos estratégica y experimentalmente) de los Objetos, oponerse no ya sólo al caos, sino a la saturación de las imágenes lanzadas, en proceso paralelo a su creciente autonomización, a una profusión vertiginosa y a una desquiciante tortura. El gesto de Malevich es el del desprendimiento no sólo de los "objetos" cotidianos, usualmente tan a resguardo en nuestras representaciones, sino también de las distancias, las diferencias, el devenir... Si el espacio del Arte debía seguir siendo el de la libertad - una libertad a salvo, refugiada al menos en lo experimental- aún era necesario encontrar la Imagen iconoclasta, la Imagen de la No-Imagen, el Objeto del No-Objeto. Eso es el Cuadrado Negro de Kassimir Malevich: reducción de la complejidad y abigarramiento de la totalidad diversa a un Casi-nada- o Nada-que-ver. Y llegó, ese Cuadrado, casi sin aviso previo (a diferencia de los procesos muy progresivos hacia la abstracción en Kandinsy o Mondrian), estimulado Malevich tan sólo por uno de los decora- 
dos de la ópera Victoria sobre el sol (1913), de los que él mismo se encargó (figura 7).

Era necesario el Negro. No estaba decidido que la abstracción debiese conducir necesariamente a una "concentración" y a una suerte de khenosis, vaciamiento o desprendimiento liberadores. La abstracción no se contradecía con el abigaramiento y esa especie de distracción a la que podríamos llamar, si aceptamos un término de Jean-Luc Marion, "saturada" 11 (figura 8) muy propia de, por ejemplo, Kandinsky, en la que la mirada puede llegar a perderse entre líneas, figuras, colores... Por su parte, la abstracción minimalista que Malevich funda se acerca al grado cero de donación "representacional", requiriendo el esfuerzo de una insólita soledad: justamente una voluntad o un pathos de desasimiento de todo lo que pudiese distraer... Pero distraer ¿de qué? De la interioridad de la subjetividad, o, en el caso de Malevich, de la inmanencia de una sensación de la que, sin embargo, podrían esperarse importantes beneficios "místicos". Es como si Malevich hubiese alcanzado con éxito lo que Descartes no pudo conseguir en su loco ejercicio de epojé de la presencia de las cosas al cogito. Se diría que el cuadrado no guarda memoria. O quizás sí, y no sólo memoria, sino el proyecto in nuce de toda Imagen por venir, y en lugar de ser Negro por encontrarse Vacío lo es, al contrario, por encontrarse lleno. Entonces, lejos de ser la imagen de la desolación y el desierto, el Cuadrado Negro sería plétora.

\section{Cogito/Effacer, to Erase}

La lección era ya, en cierto modo, cartesiana. Lo que estaría en juego sería, en suma, la (vieja) idea de que el Fundamento se erige sobre una devastación previa (casi siempre, o siempre, del Mundo). Lo que pretendía alcanzar Descartes era la inmanencia reflexiva, pura, del Cogito/Sum: un cogito iniciáticamente reducido a sí o plenamente solitario, autosuficiente en su pensamiento de sí. Y no pudo pensar hacerlo de otro modo que en un ejercicio de effacement o de borrado. El relato especulativo de Meditaciones metafisicas nos dice que comoquiera que no pudo acometer ese effacement, pretendió vengarse de la impertinencia, de la terquedad de las cosas (perceptos) elevando la hipótesis de su falsedad (reputándolos falsos, pues) y dando lugar, así, a un cogito psicologistamente inmanentizado, recluido en sus propias cogitaciones, impregnadas al principio, claro está, de falsedad. La venganza contra los Objetos que distraen del ser consigo del cogito en dirección a la supremacía del Sum, reputándolos falsos, demuestra que para Descartes no se trataba del aparecer en cuanto tal o que al menos no había llegado a comprender su cuestión, sino que era objeto principal de su interés la corrección de

${ }^{11}$ Cfr. Marion, J. -L., Étant donné. Essai d'une phénoménologie de la donation, PUF, Paris, 1997. El ejemplo que aduce Marion es el del cubismo (p. 283). 
dicho aparecer, lo que justifica la marginación cartesiana, de entrada, de los mundo onírico y de la locura. Recordemos cuando dice Descartes:

"Cerraré ahora los ojos, me taparé los oídos, suspenderé mis sentidos (je détournerai tous mes sens); hasta borraré ( $j^{\prime}$ effacerai) ${ }^{12}$ de mi pensamiento toda imagen de las cosas corpóreas, o, al menos, como eso es casi imposible (parce que à peine cela se peut-il faire), las reputaré vanas y falsas; de este modo, en coloquio sólo conmigo y examinando mis adentros, procuraré ir conociéndome mejor y hacerme más familiar a mí propio". ${ }^{13}$

Más honesto para con las cosas, en lugar de devaluarlas Malevich piensa su supresión. Si el gesto cartesiano es resentido, el de Malevich es de una suerte de tajante nihilismo. Pero no podría pasar, tal vez, de ser, como he dicho antes, una estrategia en el ámbito del "Como si..." o un atrevido experimento - que no por irrealizable, es cierto, daría menos que pensar. No era por reputar falsas las cosas de los sentidos por lo que podríamos asentir en cierto modo a Descartes, sino por la honestidad de afirmar la imborrabilidad de las cosas olo que sería lo mismo - por afirmar su perpetuo retorno (en la memoria, al cabo de los ojos, en el extremo de la imaginación... o al cabo, en suma, de un cogito). Y sin embargo, lo que Malevich tenía a su disposición era la figuración visual de la supresión de las cosas y las imágenes, aunque hubiese de recurrir a "la única imagen" superviviente de la devastación, que sería justamente la última Imagen o el Cuadrado Negro. Imagen Pura, sin objeto, después del Mundo. O anterior al Mundo, a la espera de la imposición de la Luz, o de la Mirada, o de una aparición, o de un fantasma, o tan sólo de un Punto.

El intento y el exceso de Descartes redundó en un cogito psicologizado. Por su parte, el intento y el exceso de Malevich redundó en un gesto hiperbólico de - llamémoslo así- "asistencia" a la intuición, ${ }^{14}$ pero sin futuro. Por eso, la interpretación del Negro quedaba sometida a una dramática coyuntura, pues podría suponer el emblema del fin de la Imagen y de la Pintura, o bien el de su nuevo comienzo, y tendría futuro, entonces, en lo que el Cuadrado sería capaz de abrir: un futuro para la Imagen, librada de lo "real", o abierta en otro sentido y en una nueva profundidad.

Si lo que podría vincular a Kandinsky con Descartes es la voluntad de radicalidad en el sentido de una autentificación de la experiencia, de modo que la evidencia cartesiana contra la duda se convertiría, en Kandinsky, en la nece-

12 Effacer: borrar, tachar, rayar, hacer olvidar, oscurecer, eclipsar, apartarse, echarse a un lado...

13 Descartes, R., Meditaciones metafisicas con objeciones y respuestas (tr. y notas de V. Peña), Alfaguara, Madrid, 1977, p. 31.

14 Me refiero, concretamente, a la "asistencia" en el sentido de ayuda o complemento. Allí donde la intuición inmediata no accede, el artista, el filósofo, etc., podrían brindar "medios de asistencia", ayuda o complemento con vistas a experienciar lo que el pensamiento busca en la intuición. 
sidad interior contra la inautenticidad de la experiencia artística, lo que vincula a Malevich con el fundador de la filosofia moderna es la voluntad de "arrasar" para acercarse al fundamento: el cogito/sum en Descartes, y el punto 0/1 de la Imagen, en Malevich. El cuadrado de Malevich supone el primer ejercicio radical de vaciamiento, desasimiento, khenosis, en suma, de la representación objetiva, en el sentido de la deuda contraida tradicionalmente por la mímesis con un "mundo de cosas" (paisajes, personajes, utensilios, etc., etc.), pero también incluso con el vaivén de las formas... Hay que vaciar por completo para "limpiar a fondo", "airear" el espacio, "allanar el camino"... y, en fin, en el terreno intrapictórico, para comprender la autonomía del Plano-Forma-Color sin mundo como reducto fundamental y mínimo del arte.

\section{NEGRO:}

Negro extático, de la Noche (mística), "más cierta -en Juan de la Cruzque la luz de mediodía". 15

Negro de la Noche del Universo, anunciada en aquella insinuación de telescopio a punto de abrirse que servía de fondo de decorado en "Victoria sobre el sol" (figura 7).

Negro - también - intrauterino.

Negro de la indeterminación del Hay: ${ }^{16}$ Il y a, Es gibt, antes de que aparezca esto o lo otro. Negro de presagio, o de premonición. Negro de Horizonte.

Negro - o Penumbras - de. Descenso-de-Telón para que, ahora sí, más que antes, "comience la Representación", más sabia, más libre.

Negro de tránsito, o de transición.

\section{BLANCO:}

De Lienzo, o de Papel-en-blanco.

$\mathrm{O}$ de Pared o de Pantalla. ${ }^{17}$

Y sería necesario, imprescindible, no caer en la tentación de aquello mismo contra lo que el Cuadrado Negro combate, es decir, no caer en la tentación de absorber objetivamente el Cuadrado como objeto. Al Cuadrado se lo

15 Vid. nota 3.

16 Me refiero, claramente, a Emmanuel Lévinas. A expensas de no poder entretenernos en ello, cfr. Lévinas, E., De l'existence à l'existant, Vrin, Paris, 1978, pp. 93 y ss. (Existence sans existant). Las aproximaciones descriptivas levinasianas son extremadamente interesantes, con la salvedad de que, respecto a esa oscuridad a la que Lévinas se refiere, quizás Malevich la viviese en un sentido más liberador y místico, próximo a la "noche" de Juan de la Cruz (vid. nota 3).

17 En todo caso, sobre la significación de los diferentes cuadrados negro, blanco o rojo, y la relevancia del blanco y del negro, cfr el texto "El suprematismo" de K. malevich (1920, cit. en cit. en AA.VV. (A. González García, F. Calvo Serraller y S. Marchán Fiz, eds.), Escritos de arte de vanguardia, Istmo, Madrid, 1999, pp. 295-299. 
ha de experienciar interiormente, penetrando en él, trasladándose a su adentro para vencer la resistencia aún objetiva de su presencia de lienzo y poder acceder al Entre de lo que Bachelard llamaría su - o nuestra - inmensidad intima, fuera de su perímetro. ${ }^{18}$ Rothko aprendió la lección y trabajó sistemáticamente con lienzos de enorme tamaño, más a escala humana, ${ }^{19}$ para que el que contemplase uno de sus colour fields difuminados, espectrales, etéreos, pudiese penetrar mejor en su profundidad

\section{Sin-objeto y sensación}

Bien visto, nada de extraño tiene que el Sin-Objeto de la abstracción minimalista de Malevich debiera encontrar su apoyo en el suprematismo de la sensación pura. Es como si ya no se buscara salir, fuera, sino demorarse en ese existir que se aviene al No-Objeto. Para Malevich lo decisivo de la pintura no es lo representado - nunca lo habría sido -, sino la fuerza y necesidad interiores de eso representado y, sin duda, el efecto provocado. El significado del "suprematismo" se refiere fundamentalmente al "sentimiento puro" que resta (diríamos que "diferencialmente") tras el abandono de "los fenómenos visuales del mundo objetivo", que carecen de sentido. Para el autor de Un mundo sin objeto,

18 Cfr. Bachelard, G., La poética del espacio [1957], FCE (Breviarios, 183), Buenos Aires, 1991, p. 221: "Si pudiéramos analizar las impresiones de inmensidad, las imágenes de la inmensidad o lo que la inmensidad trae a una imagen, entraríamos pronto en una región de la fenomenología más pura -una fenomenología sin fenómenos o, hablando menos paradójicamente, una fenomenología que no tiene que esperar que los fenómenos de la imaginación se constituyan y estabilicen en imágenes acabadas para conocer el flujo de producción de las imágenes. Dicho de otro modo, como lo inmenso no es objeto, una fenomenología de lo inmenso nos devolvería sin circuito a nuestra conciencia imaginante. En el análisis de las imágenes de inmensidad realizariamos en nosotros el ser puro de la imaginación pura. Aparecería entonces claramente que las obras de arte son los subproductos de este existencialismo del ser imaginante. En esta vía del ensueño de inmensidad, el verdadero producto es la conciencia de engrandecimiento. Nos sentimos promovidos a la divinidad del ser admirante.

Desde entonces, en esta meditación, no estamos "lanzados en el mundo" puesto que abrimos en cierto modo el mundo al rebasar el mundo visto tal como es, tal como era antes de que soñáramos. Incluso si tenemos conciencia de nuestro ser raquítico -por la acción misma de una dialéctica brutal- tomamos conciencia de la grandeza. Nos vemos entonces devueltos a una actividad natural de nuestro ser inmensificante.

La inmensidad está en nosotros. Está adherida a una especie de expansión de ser que la vida reprime, que la prudencia detiene, pero que continúa en la soledad. En cuanto estamos inmóviles, estamos en otra parte; soñamos en un mundo inmenso. La inmensidad es el movimiento del hombre inmóvil".

19 Hess, B., Expresionismo abstracto, Taschen, Köln/Madrid, 2005, Cfr. p. 72.Se puede encontrar una magnífica descripción de un lienzo de Rothko en el cap. 13 de Sandler, I., El triunfo de la pintura norteamericana. Historia del expresionismo abstracto, Alianza Editorial (Alianza Forma 136), Madrid, 1996, pp. 197-204 (especialmente pp. 202-203). 
Una representación objetiva, puesto que tiene la objetividad como fin, es algo que no tiene nada que ver con el arte y, sin embargo, el uso de las formas objetivas en una obra no excluye la posibilidad de que tenga un alto valor artístico.

Por lo tanto, para el suprematista, el apropiado medio de representación es siempre aquel que ofrece la más completa expresión del sentimiento como tal, y que ignora el aspecto familiar de los objetos.

La objetividad en sí misma no tiene para él sentido alguno; los conceptos de la mente consciente carecen de valor.

El sentimiento es el factor determinante..., y así, el arte llega a la representación no objetiva, al suprematismo.

Llega a un "desierto" en el cual nada puede percibirse excepto el sentimiento.

Todo lo que determina la estructura ideal-objetiva de la vida y del 'arte' ideas, conceptos, imágenes - lo aparta de sí el artista para atender al sentimiento puro $^{20}$

Y un poco después, este texto decisivo:

El ascenso a las cimas del arte no objetivo es arduo y penoso... Pero, sin embargo, gratificante. Lo conocido queda cada vez más atrás... Los contornos del mundo objetivo se van difuminando progresivamente, paso a paso, hasta que por último el mundo mismo [...] se pierde de vista.

¡No más 'semejanzas con la realidad', no más imágenes idealistas: sólo un desierto!

Pero este desierto está habitado por el espíritu de la sensación no objetiva, que lo llena todo.

Incluso yo mismo llegué a sentir una especie de timidez que bordeaba el temor cuando abandoné 'el mundo de la voluntad y de la idea' en el que había vivido y trabajado, la realidad en que había creído.

Pero un dichoso sentimiento de la no-objetividad liberadora me acercó más al 'desierto', donde nada es real excepto el sentimiento... Y éste llegó así a ser la sustancia de mi vida.

No se trataba del 'cuadrado vacío' que había expuesto, sino del sentimiento de la no-objetividad.

Comprendí que la 'cosa' y el 'concepto' habían sido sustituidos por el sentimiento, y comprendí la falsedad del mundo de la voluntad y de la idea ${ }^{21}$

También en otro texto titulado "Inobjetividad y suprematismo", de 1922-1923, insiste Malevich en estos pormenores, reivindicando muy enfáticamente que el suprematismo significa "la Nada liberada", y dice:

20 Malevich, K., "Suprematismo”, art. cit. p. 367.

21 Ibid., p. 368. 
Suprematismo como mundo inobjetivo o 'la nada liberada'. En este punto partí de la idea de que todo allí era como la 'nada', hasta que el hombre se puso a conocer el mundo con todas las concepciones y experimentos. Con ello creó una vida bajo la pregunta permanente por el 'qué'. El suprematismo libera al hombre de esta cuestión [...] El suprematismo no sirve a nada ni a nadie, ya que se encuentra en la igualdad inobjetiva o en el peso-cero. Es la 'nada' a la pregunta de la generalidad por el 'qué,22

Quizás podría decirse que la "experiencia" que buscaba Malevich era casi "sin órganos", incapaz de "desterritorializar", volcada en la búsqueda de una suerte de "retención" cabe-la-sensación, sin la premura ni la ansiedad de la "exterioridad", concentrada en alcanzar una hipersensibilidad de "estar a la espera": allí donde como en el Cuadrado negro nada hay(-que-ver), la única posibilidad de salvación es la sensación como reflexión y la expectativa de Algo, por mínimo que sea: bastaría el más leve indicio, huella, luz, tal vez un punto, una pequeña línea, un matiz... para que se produjese la apertura.

Cuando leía a Malevich me preguntaba con frecuencia si habría de extrañarnos que muchos años después apareciese en Michel Henry ese vínculo, tan singular, entre la crítica al éxtasis objetivo de la intencionalidad volcada sobre objetos (tal como Henry concibe que Husserl interpreta la intencionalidad de la conciencia), y la reivindicación de la Sensación y la Vida. En efecto, podría resultar muy relevante el recíproco esclarecimiento que se brindarían Michel Henry y no tanto Kandinsky, como piensa el propio Henry, sino, mucho más y mejor, Kassimir Malevich. Si bien asiste a Henry toda la razón al asignar a Kandinsky el descubrimiento de la innere Notwendigkeit, ${ }^{23}$ considero que la abstracción minimalista de Malevich da cuenta del "suprematismo" de la sensación en Henry mejor de lo que lo haría la abstracción saturada en Kandinsky. Por su parte, Henry nos ayuda a comprender la quererencia de la abstracción por la necesidad (interior) y por la inequívoca supremacía de la sensación (Malevich/Rothko). Independientemente de que Henry conociese con suficiente detalle el vínculo en Malevich entre abstracción "geométrica" (o protogeométrica) y supremacía (suprematismo) de la sensación, quizás el fenomenólogo francés encontró que en la "pasión" colorista kandinskiana se apreciaba mejor el ser original de la impresión que en las formas de Malevich. Pero lo que decía Henry de la abstracción kandinskiana se confirma mucho más ante el Cuadrado negro de Malevich, a saber, que la abstracción "implica [...] una puesta fuera de juego global del mundo, que no nos deja por ello en presencia de una nada, sino de lo que somos en nuestro más profundo ser". ${ }^{24}$

22 Malevich, K., "Inobjetividad y suprematismo", cit. en AA.VV., Escritos de arte de vanguardia, op. cit., p. 331.

23 Este aspecto lo desarrollamos en "El hervidero interior", Sileno (Madrid) 10 (2001), pp. 13-28.

24 Henry, M., "Kandinsky y la significación de la obra de arte" [1987], en Fenomenología de la vida, Columna, Barcelona, 1991, p. 125. 
Henry cita un fragmento de la conferencia de Colonia en el que recuerda Kandinsky

el gozo absoluto y el entusiasmo que me causaba el color. A menudo, una mancha de un azul límpido y de una poderosa resonancia percibida en la sombra de una espesura me dominaba tan intensamente que pintaba un paisaje entero para plasmar esta mancha. Evidentemente, el estudio tomaba mal sesgo, y yo me esforzaba por buscar 'motivos' la totalidad de cuyos componentes actuasen con una misma intensidad en mi espíritu. ${ }^{25}$

\section{Para Henry,}

La finalidad del arte no es expresar un estado subjetivo, entendido como un estado de hecho o como una situación; es en ese sentido que Kandinsky pudo decir: 'No pinto estados de ánimo'. El arte pinta la vida, vale decir, una potencia de crecimiento, pues la vida en cuanto subjetividad, es decir, en tanto un hacer la experiencia de sí, es justamente el poder de arribar a sí, y de este modo acrecentarse de sí en cada instante. Por esta razón, es que cada ojo quiere ver aún más de lo que ve, y cada fuerza de llenarse de sí, volverse aún más eficaz y más fuerte. El arte es la tentativa siempre reemprendida de llevar los poderes de la vida a su más alto grado de intensidad y, así, de placer; el arte es la respuesta que la vida da a su esencia más íntima y al querer que la habita, a su deseo de superación. ${ }^{26}$

¿Acaso, entonces, no podríamos encontrar un íntimo vínculo entre el Sin-Objeto de Malevich, con su suprematismo de la sensación, y la afirmación en Henry de la invisibilidad de la (archi-inteligibilidad de la) Vida, irreductible al ser-en-el-mundo ${ }^{27}$

Ajustémoslo, pues, en términos de Henry: la vía mística, abierta por Malevich, de aproximación a la Vida en la hondura del no-éxtasis hacia la exterioridad del Mundo, iba a colapsarse en breve, y en muchos frentes: desde la avalancha del caos de lo real que suscitaba admiración en los dadaístas, y la fascinación surreal por los objetos, hasta, sobre todo, en un "cambio de tercio" impresionante, la aniquilación a que, en torno a 1932/1937, los totalitarismos comunista-soviético y nacionalsocialista sometieron - lo diré con el rótulo alemán - el entartete Kunst (arte degenerado, deformado). Sin embargo, antes de dicha aniquilación (exilio global de la vanguardia), restaban tendencias donde la brutalidad de la vida, el deseo y el misterio aún iba a encontrar una

${ }^{25}$ Kandinsky, W., "Conferencia de Colonia" [1914], en La gramática de la creación/El futuro de la pintura, Paidós, Barcelona, 1996, p. 52 (cit. por Henry, M., art. cit., pp. 130-131).

${ }^{26}$ Henry, M., art. cit., p. 133.

${ }^{27}$ Cfr., especialmente, Henry, M., Encarnación. Una filosofia de la carne [2000], Sígueme, Salamanca, 2001, § 15 (pp. 113 y ss.). 
expresión suficiente. Y seguiría en ellas expresándose la vida, aun sin aquella mística de la Sensación pura, en el Exceso y el Misterio.

\section{Sobre el retorno hiperreal y surreal del Objeto}

Aunque no respondiese directa o inmediatamente al desafío del "Cuadrado Negro", es más, incluso en abierto (pero también dialéctico) enfrentamiento con su radical minimalismo, podría plantearse como hipótesis que los tres grandes movimientos de la postguerra europea que no siguen la línea de la abstracción (no nos referimos, pues, al neoplasticismo de Mondrian ${ }^{28}$ y Van Doesburg, que sí la siguen) responden a sensu contrario, sin escatimar radicalismo en ningún caso, a ese Vacuum, o a esa Plétora de Malevich. En fin, se trata de lo que, a partir de ese Cuadrado Negro, estaba por venir:

a) la prosecución del expresionismo en el hiperrealismo (respecto al tema) de la Nueva objetividad (Neue Sachlichkeit), representada eminentemente por Grosz y Dix (también Beckmann y otros), que se opone con una extraordinaria fiereza a los desarrollos burgueses y metafísicos de la pintura. ${ }^{29}$ Para Dix

28 Consideremos, por un momento, su New York City, de 1942, para calibrar el radicalismo y provocación de su "estilo".

29

"Es un error creer, cuando uno pinta peonzas, cubos o caos mentales profundos, que se es revolucionario, tal vez en oposición a Makart. ¡Contemplad a Makart! Es un pintor de la burguesía, pinta sus anhelos, sus contenidos y su historia, ¿vosotros?, ¿qué sois sino alabarderos plañideros de la burguesía? Vuestras ideas snobistas, vuestros pensamientos particulares, ¿a quién los relacionáis? ¿Trabajáis algo para el proletariado que será el portador de la cultura del futuro? ¿Os esforzáis por vivenciar y comprender las ideas del mundo del proletariado y de enfrentaros a los explotadores y sus apoyos'? ¡Cuántas cosas podríais hacer aún! Preguntaros si ya no es tiempo de abandonar vuestras decoraciones nacaradas. Pretendéis ser intemporales y estar por encima de los partidos, vosotros, guardianes de la "torre de marfil", pretendéis crear para los hombres. ¿Dónde está el hombre? ¿Qué es vuestra indiferencia creadora y vuestra chochería abstracta de la intemporalidad más que una especulación ridícula e inútil sobre la eternidad? Vuestros pinceles y plumas, que deberían ser armas, son huecas cañas de paja. [...] Yo aspiro a ser comprensible a todo hombre; renuncio a la profundidad exigida actualmente, a la que no se puede llegar sin una verdadera escafandra, repleta de farsas cabalísticas y de metafísica intelectual" (Grosz, G., En vez de una biografia [1925], aparecido en Katalog der Ausstellung, Kunsthandlung Würthner, Wien y Flechtheim, incluido en Die Kunst ist in Gefahr, Malik, Berlin, 1925, cit. en AA.VV., Escritos de arte de vanguardia, cit. supra, Madrid, 1999, pp. 132-133. Cfr., sin embargo, por ejemplo, de 1920, su cuadro "Sin título", que presenta a un hombre/maniquí en una ciudad desértica, industrial y geométrica. El motivo no es nada hiperrealista, pero no por ello es menor su potencia crítica (por lo demás, inequívoca). También resulta interesante el testimonio crítico de Nokolai Tarabukin en su texto Del caballete a la máquina, de 1922, cuando sostiene que "si la conciencia artística de nuestros días no se satisface ni con el naturalismo, con sus anécdotas y sus colores, ni con el impresionismo y sus tentativas para crear mediante el color la ilusión de atmósfera terrestre, de la sombra y de la luz, ni con el futurismo y su voluntad estéril, contradicho in adjecto, 
el objeto sigue siendo lo primario y la forma es configurada por el objeto. Por este motivo, siempre ha sido para mí de mayor relevancia la cuestión de si me acerco lo más posible a la cosa que veo, pues para mí el qué es más importante que el cómo. El cómo se desarrolla a partir del qué..$^{30}$

$\mathrm{Y}$, sin embargo, no se trataba ni se trata nunca sólo de la "cosa que veo", sino también de cómo la veo -y los representantes de la Neue Sachlichkeit solían verla hiperreal, despiadada, brutal.

b) el dadaísmo. El "Cuadrado Negro" es tanto desenlace, epílogo, como apertura, diafragma de una enorme eclosión de fenomenalidad que encontrará su refrendo plástico en un grupo de experiencias cuya novedad estriba, más que en la experiencia misma, en el sistematismo de su práctica: pienso, sobre todo, en

1) el Poema dadá (1920), vinculado, sin duda, con su antecedente: el lenguaje alógico o "transmental" zaum (futurismo ruso, Kruchenykh, 1913) y con la escritura automática (surrealismo) (1920: Les champs magnetiques); aunque dadá potencie el absurdo, éste había ya aparecido antes de la guerra del 14 . ¿Quién se lo enseñaría al Malevich de, por ejemplo, Vaca y violín? Pero la imagen pura debía estar libre del Absurdo, y ello sólo podría suceder si previamente no hubiese un mundo "cuerdo" que destrozar, sino Nada: tan sólo un Cuadrado Negro.

2) la orgía Merz o la Merzbau, de Kurt Schwitters (a partitr de 1923), desaforada, loca acumulación, típicamente dadaísta, de Objetos de todo tipo. El antecedente de estas prácticas se localiza en 1913, en el ready-made de Duchamp, y en la inmensa des-axiologización a que se vincula el futurismo. ${ }^{31}$

de conseguir en un lienzo estático la representación cinética de las formas dinámicas de la vida, nos parece que tampoco puede satisfacerse con los suprematistas y su absurdo Cuadrado negro sobre fondo blanco, con los facturistas no-objetivos y sus sempiternas experiencias de laboratorio sobre la superficie del lienzo, con los constructivistas que imitan ingenuamente las construcciones técnicas sin conferirles la finalidad utilitaria que es su razón de ser y finalmente con todos aquellos que trabajan a partir de materiales por el material y crean las formas sin objeto de un arte separado de la vida. En sus creaciones "más izquierdistas", el arte actual se ha encerrado en un callejón sin salida. Al trabajar sobre la forma 'pura' y sólo sobre ella, el artista ha acabado por privar de sentido a su actividad creadora, porque jamás nos satisfacemos con la forma desnuda y vacía, ocupados como estamos siempre por buscar un contenido. El "cuadro" del artista del pasado encontraba su sentido en el efecto estético esperado por su autor. La construcción de un maestro contemporáneo ha perdido este último sentido, porque la 'estética' ha sido conscientemente desterrada desde el día en el que se dio el primer paso en la dirección de un arte nuevo" (cit. en íbid., pp. 318-319). 
3) El collage, que acredita la relacionalidad y la composición de heterogeneidades extremas tanto como recurso crítico como en tanto recurso poético (metafórico);

De la Verdad brutal, a ras de suelo y sin trascendencia, de la Nueva objetividad a la Verdad-Avalancha del dadaísmo. Es la experiencia del "todo se nos viene encima" o del aplastamiento por exceso, desmesura y caos. Se trata, sin duda, del post-festum del futurismo. Atrás quedó el forzudo futurista, que ya no aguanta el peso y la opresión de lo real, el caos cotidiano, el sinsentido (y la injusticia). Y, sin embargo, aun ríe con desesperación. De la Verdad-Futuro del futurista queda sólo, ahora, una Verdad-Caos. Pero no se trata sólo de una verdad "negra". El año crucial es 1913: tras lentos y esforzados preparativos será el año, si hubiera de señalarse alguno, de la Inclusión absoluta. Un año, sin duda, de graves presentimientos. En otros trabajos he insistido en la relevancia del principio de todos los principios de la fenomenología husserliana ( $§ 24$ de Ideas I) como apertura inclusiva de todo-lo-que-se-da en tanto se da. Ese mismo poder de inclusión, vinculado a la necesidad interior, había sido afirmado por Kandinsky hacia $1910,^{32}$ y en 1913 los ready-made de Duchamp destruyen el canon, o el corsé de la etiqueta "Arte". Luego, a Malevich le corresponderá el "apagón": hágase la oscuridad... Eso sí, luego podrá aparecer un portabotellas, o unas botas de campesino, o el Titanic (14 de abril de 1914), o tal vez una rosa, o un Cadeau (Man Ray), pero también una campesina rusa, o quién sabe si aquellas escenas de los dibujos de Grosz y Dix. El Cuadrado negro no-deja-ver-nada para, en el fondo, poder dejar-paso a Todo. Salvando las distancias (necesarias), ese Cuadrado Negro es como la angustia, que aproxima la Nada al Todo y el Todo a la Nada. Y se habrá tenido, entretanto, que sostener su presencia, mantenerse ante su Negrura.

c) el surrealismo, Respecto a la presencia de los Objetos, ${ }^{33}$ no se trataría de amontonarlos (Totalidad-Informe dadá) ni de suprimirlos (Nada, Cuadrado negro suprematista), sino de ganar una nueva, insólita o extraña singularidad de los Objetos. Fascinado por las posibilidades ontológico-metaforizantes del Collage (al que acabo de referirme en b3) y por otras de inmensa concentración ("pasional" casi) en torno a Objetos de funcionamiento simbólico casi todos (en feliz expresión de Salvador Dalí),${ }^{34}$ el surrealismo buscará y creará objetos por doquier. Y, sin embargo, lo que conecta el Vacuum o la Plétora de

dad, complejidad y axiología", en Escritos de Filosofia (Buenos Aires) 44 (2004), pp. 139-162 .

${ }^{32}$ Tal es el asunto principal de Moreno, C., "El hervidero interior", art. cit.

${ }^{33}$ Magnífica la recopilación de imágenes y el texto de la exposición sobre El objeto surrealista (IVAM, Centre Julio Gonzalez, 16 de Octubre de 1997-4 de Enero de 1998), con texto a cargo de Emmanuel Guigon, IVAM, Valencia, 1997.

${ }^{34}$ Cfr. Dali, S., ¿Por qué se ataca a la Gioconda? Siruela, Madrid, 1994, en especial los textos "Objetos surrealistas" (pp. 123-126), "Objetos psicoatmosféricos-anamórficos" (pp. 139-143) y “iHonor al objeto” (pp. 196-199). 
Malevich con el Objeto surreal no es nada relativo a ese "funcionamiento simbólico" del Objeto, del que he dicho, en otra ocasión, que es un "objeto en rebeldía". Lo que conecta aquel Vacuum o Plétora con el Objeto surreal es la invisibilidad de éste y el misterio y la inquietud que provoca, que potencia no ya la sensación pura (suprematista) ni el aturdimiento (Todo dadá), sino el paso decidido a lo Imaginario, movido por la Ausencia. En esta Ausencia, más concreta, del Objeto surreal, ante todo Objeto Invisible, se ha convertido el Negro de Malevich.

Me represento, entonces, tres escenas o escenarios posibles:

Escena I. Luis Buñuel/Salvador Dalí, Un chien andalou, 1928. Un ojo es rasgado (figura 8). Coincidiendo, en delirante desplazamiento, con una línea de nube cortando la Luna, una navaja de afeitar portada por un joven Buñuel en éxtasis lunático rasga, corta un Ojo. Que se haga espacio en la Imagen, pues, a un mundo sin-sentido y enigmático. Hay que cerrar los ojos - por lo menos una vez en la vida - en seguimiento, aunque en otro sentido, de aquella epojé cartesiana recordada por Husserl al comienzo de sus Cartesianische Meditationen. ¿Acaso no hizo eso Malevich? ¿O quizás mantuvo muy bien abiertos los ojos con la intención de ver incluso eso: no la no-Imagen, sino el Sin-Objeto, para rescatar un Pre-Mundo: Cogito, apertura trascendental (Husserl), Physis/Ser/Tiempo (Heidegger)? ¿No es verdad que el Pre-Mundo también podría aparecer como Sur-realité? En efecto, en 1915 estaba por llegaraunque es cierto que había sido descubierta mucho antes- una de las modalidades del Objeto más extraordinarias inventadas después del Objeto-Cosa, el Objeto-Util y el Objeto científico: el Objeto surreal, al cabo del Deseo, curtido en la Falta o la Ausencia.

Escena II. Alberto Giacometti, L'Objet invisible (1934-1935) (figura 9). Una figura con reminiscencias en la escultura africana deja un hueco entre sus manos para algo que no vemos, que está ausente. La trampa consiste en denunciar, o mejor, en proclamar que allí, entre esas manos, hay espacio para un Objeto desconocido, invisible, pero Objeto. Es el momento de Imaginar.

Escena III. En El nacimiento del objeto (1929-1930) (figura 10), Paul Nougé situó el nacimiento del Objeto no sólo en el entrecruzamiento de miradas (intersubjetividad), sino sobre todo en esa especie de avidez en el afán-de-ver que muestran los personajes de la foto. Al nacimiento del Objeto no le sería necesario ante todo una intersubjetividad (a la que sin duda requiere), sino primeramente un interés, un acercamiento casi pulsional, incompatible con la indiferencia de la(s) Mirada(s). Qué importa que ese Objeto in statu nascendi no se vea (por el momento). Si hay esa pasión por el Objeto, éste está ya ahí, como lo está en la proclamación, allí, en el hueco de las manos, del Objeto invisible.

¿Aparecerá, pues, Algo al fondo? ¿Podemos, debemos esperarlo? ¿O habría que enfrentarse radicalmente no con el Negro, sino con nuestra propia tendencia, o nuestro instinto-de-Objeto(s)? ¿No es contra nosotros mismos 
contra lo que Malevich nos fuerza, o nos invita, a combatir? Es casi como si la contemplación de lo Monocromo fuese una ayuda para resistir a la tentación de huir, una vez más, inexorablemente, hacia los Objetos, cediendo a nuestra congénita ansiedad-de-Mundo(s). En dirección a Rothko, desde la descomposición cubista de los objetos pasando por Kandinsky y especialmente por este Cuadrado Negro de Malevich, la pintura se aproxima a la existencia. Ni siquiera al espíritu que, como sabemos, se nutre de bellas formas, otras vidas (compartidas o narradas), palabras, sabores... sino a la existencia nuda o a la vida más acá de un proyecto de Mundo. Para devolver a sí misma a la existencia, o a la Vida, hay que practicar esa khenosis ascética ante el Cuadrado Negro. La música se encontraba, sin duda, en ese camino hacia la Inobjetividad y, a su través, hacia la Existencia. Pero se dejaba confundir demasiado - también ella - con los estados de ánimo. La aventura de Malevich fue - lo estimo así mucho más difícil, al escoger como compañera de viajes del éxtasis existencial (y místico, en su caso) a la Geometría. Pero en música iba a ocurrir algo similar. Aparte de la "máquina de ruidos" de Russolo, hacia 1909 aparecen las atonalidades de Arnold Schönberg y luego, en 1913, el escándalo de La consagración de la primavera de Stravinsky. Habrá que esperar hasta llegar a 1952. Un episodio de la amistad entre John Cage y Robert Rauschenberg resulta extremadamente esclarecedor. La pieza 4,33, de John Cage, data de 1952. Nada-que-escuchar: 4,33 minutos de silencio. De un año antes son las White Paintings de Robert Rauschenberg: Nada-que-ver, Blanco. Un Cuadro en Blanco. Ni siquiera márgenes, ni dinamismo alguno. Nada, Blanco. ¿Podría llegarse más lejos? Si en Pintura para acceder a la Imagen "pura" hacía falta el Sin-Objeto, para acceder, en Música, al Sonido hacia falta la No-melodía. No se trataba del No-Ver ni del No-Escuchar, sino de que no quedasen ocultas la Imagen y el Sonido por los objetos y las melodías. Y entonces Imagen y Sonido, así comprendidos, desde esas epojés, nos acercarían a la comprensión de la existencia, o la Vida. Un año después de aquella pieza de John Cage, en 1953, Robert Rauschenberg pidió un dibujo a tinta a Willem de Kooning y lo borró, creando algo nuevo en el acto de borrar. Y se mostró, finalmente, el Proceso.

Una de las lecciones fenomenológicas de estas experiencias es su relevancia y, al mismo tiempo, su excepcionalidad. Demuestran que el único destino de la conciencia no es el Objeto, pero también, de inmediato, que nuestra situación fenomenológica y existencial es la de una vida-que-experiencia-mundo (en expresión husserliana: welterfahrendes Leben), y que la alteridad de mundo y de objeto, el estímulo, el reto y la resistencia que brindan son imprescindibles a la mirada, a la escucha, al tacto... Si el límite de la Inobjetividad está en la Continuidad (para representarlo se recurre a lo Monocromo), tendría razón, sin duda, Maurice Blanchot al insistir en que el Fondo del Ser revela esa Continuidad pero que el hombre, con su malestar ante la continuidad, y comoquiera que también él forma parte del fondo del ser, revelaría -el 
hombre- que al fondo del Ser pertenece tanto la Continuidad como la Discontinuidad $^{35} \mathrm{o}$ - digámoslo así, en el presente contexto de este ensayo - el Plural originario de la conciencia y su otro, y el Plural de los Objetos. Pero, ¿no es cierto que la relevancia, el despuntar del Objeto se enfatiza desde la ausencia parcial o casi-total? Las ausencias parciales o restrictas hacen buscar este o aquel objeto, que se deja anunciar o insinuar en ahuecamientos y huellas mientras que la ausencia global - por lo demás, irrepresentable - apela al Objeto en general, ni siquiera como Objeto, sino como Ente, Acontecimiento, Cosa. Pero siempre vinculado: una ausencia-vinculada: al Ojo, a las Manos... No se trata de que el Órgano - ojos, manos... - "perfile" adivinatoriamente el Objeto o su identidad. Lo decisivo es la apelación a las manos, a la mirada... o, en el fondo, al espectador, o al Testigo del Aparecer. Lo relevante de $E l$ objeto invisible y Nacimiento del Objeto es la intensidad de la Ausencia... al cabo de unas acogedoras manos o unas miradas ávidas, ya intersubjetivamente vinculadas no por la identidad de este o aquel objeto, decíamos, sino por la expectativa (naciente) del Objeto. Lo que enseñan es esa pasión-de-Objeto, instinto, pulsión-de-Objeto. Qué importaría si no se lo pudiera ver o estuviese por-ver, si, sin embargo, se lo pudiera pre-sentir. Se trata de la "curiosidad", de la "concupiscencia del ver", que es índice, ante todo, de una verdad radical de la conciencia. ¿Y acaso no reta a esa concupiscencia el Cuadrado Negro? Cuando, en un documental de la BBC dirigido por David Thompson (2000) dedicado a Rothko explicaba Sean Scully cómo un joven se detuvo ante un cuadro de Rothko y se quedó mirándolo con detenimiento, como si estuviese buscando allí algo o tal vez porque se le hubiese caído allí dentro, en el lienzo, su abrigo y trataba de rescatarlo, decía Scully que ése no era el modo de mirar un cuadro de Rothko, añadiendo que

No hay que concentrarse, ya que no se trata de hacer una suma. No hay ninguna respuesta ahí dentro, es una experiencia. Es algo que debería enriquecer nuestras vidas, en la medida en que cuanto más nos acercamos a los cuadros más fortalecemos nuestra relación con ellos

Scully no supo comprender aquella pulsión. No debió reducirla a anécdota, para despreciarla, sino que debió intentar comprender que toda la abstracción se alimenta de ser crítica e inquietante para con, justamente, la voluntad-de-Objeto. Esto también forma parte, sin duda, de esa "experiencia" que Scully reclamaba, a no ser que quisiéramos sumirnos en el olvido del desafío que, en sus primeros pasos, supuso la abstracción para la mirada "en actitud natural" en la vida-que-experiencia-mundo.

${ }^{35}$ Cfr. Blanchot, M., "El pensamiento y la exigencia de discontinuidad", en El diálogo inconcluso, Monte Avila, Caracas, pp. 27-37 


\section{Epílogo (contra epitafio)}

Y ya para finalizar. Después del extremo minimalismo del Cuadrado Negro, Malevich volvió a la senda de una sui generis "figuración". Pintó campesinos ataviados al modo suprematista y, muchos de ellos, como maniquíes sin rostro. Explorar el porqué de ello nos llevaría muy lejos y no es, en absoluto, nuestro propósito aquí desentrañarlo. $\mathrm{Al}$ final de su vida, en el horizonte opresivo de la cultura oficial del "realismo socialista" (en especial desde abril de 1932), Malevich pintó también retratos muy realistas. La Vanguardia se tornaba, de pronto, Resistencia. Concretamente, dos años antes de su muerte y de que en la cabecera de su lecho fúnebre fuese expuesto su Cuadrado negro, en 1933, volvió a Malevich la Ausencia -que nunca le había abandonado, aunque fuese bajo la figura inquietante de los Sin-rostro. Se trataba de dos ausencias tan disimuladas como, a mi juicio, significativas, sobre las que apenas era necesario atraer la atención como poco después habrá de hacer Giacometti con su "Objeto invisible", al que antes nos referimos. No, no era necesario nombrar nada. Eran, esas ausencias, como mensajes ocultos ahuecados en las manos serenas del propio Malevich, en su autorretrato, y de una campesina. En la mano derecha de Malevich (figura 12), por la forma que adopta, se insinúa la esquina inferior de un Cuadrado، Por su parte, entre sus manos y brazos, la trabajadora (figura 13) parecía acoger un niño muy pequeño, casi recién nacido. Tres años antes, en 1930, Malevich había pintado a lápiz una maternidad de rostro triste, que llevaba en sus manos/brazos un niño pequeño -negro. Quizás, después de todo, se estuviera insinuando en todo ello que la descendencia de Malevich habría de ser un Cuadrado Negro, o un Niño negro, casi, quizás, como aquel Niño de las transformaciones del Zaratustra de Nietzsche, abierto a ese Tiempo Venidero del que nosotros, aquí y ahora, convocados por aquel Cuadrado podríamos, quién sabe, formar parte. 
